J. Lake Sci. (湖泊科学), 2007, 19(5) :604-610

http:// www. jlakes. org. E-mail: jlakes@ niglas. ac.cn

(c) 2007 by Journal of Lake Sciences

\title{
无锡五里湖环境综合整治对旅游价值的影响评估”
}

\author{
黄和平 $^{1,2}$,万 群 ${ }^{1}$, 张 炳 $^{1}$, 毕 军 $^{1 * *}$ \\ (1: 污染控制与资源化研究国家重点实验室, 南京大学环境学院环境管理与政策研究中心, 南京 210093) \\ ( 2 : 江西财经大学资源与环境管理学院,南昌 330032)
}

摘 要: 条件价值法是目前环境经济价值货币化评估中最为广泛应用的方法. 以无锡市五里湖环境综合整治为例, 在对 条件价值法回顾总结的基础上,通过对受益周边地区居民及外地游客的面对面直接问卷调查,对周边旅游环境的改善所 带来的旅游支付意愿及影响因素进行了评估和分析, 结果表明: (1) 游客对五里湖综合整治后总的支付意愿为 2.49 亿元/ 年, 比整治前多 0.68 亿元/年, 占当地旅游总收人的 $1.49 \%$; (2) 游客的支付意愿与其收人成正比, 与其年龄也基本为正 相关关系, 而与其受教育程度的关系比较复杂; (3) 游客对五里湖景区满意度表现最差的是娱乐设施, 其次是购物、住宿 的便利性和水面的表观形象,表现最好的是空气质量和其安静的氛围. 本文最后对本次采用的调查方法与国内外广泛应 用的双边界二分式 CVM 进行了有益的对比和讨论, 并对环境综合整治为当地带来的经济和社会绩效提出了期望, 以期为 其相应的政策措施的制定和环境资源资本的运作及管理提供理论依据.

关键词:五里湖;环境综合整治;旅游价值;条件价值法;支付意愿

\section{Evaluation on tour value with comprehensive environmental regulation in Lake Wuli, Wuxi}

\author{
HUANG Heping ${ }^{1,2}$, WAN Qun ${ }^{1}$, ZHANG Bing ${ }^{1} \&$ BI Jun ${ }^{1}$
}

(1: State Key Laboratory of Pollution Control \& Resource Reuse, Center for Environmental Management \& Policy, School of Environment, Nanjing University, Nanjing 210093, P. R. China)

(2: School of Resource \& Environmental Management, Jiangxi University of Finance \& Economics, Nanchang 330032 ,P. R. China)

Abstract: Contingent value method ( CVM) has become the most popular method applied in monetary evaluation of economic value of environment by now. Taking the comprehensive environmental regulation of Lake Wuli ( Wuxi) for example, based on the review and summary of contingent value method (CVM), the tourists'willingness to pay (WTP) and its influence factors thanks to the improving of the tour environment around the lake were evaluated and analyzed through the face-to-face questionnaire investigation on local residents and endemic visitors. The results showed that: (1) the total WTP of tourists after the comprehensive environmental regulation was 249 million yuan per year, which was 68 million yuan more than that before the comprehensive environmental regulation and accounted for $1.49 \%$ of the total income of local tourism; (2) there was a positive correlation between the WTP of the tourists and their income, so as to their age, but when their education degree was considered, the relationship was complicated; (3) the entertainment facilities of Lake Wuli's scene got the least satisfaction of tourists, the next was the convenience of shopping and living, as well as the scene of the water surface; on the contrary, the air quality and tranquil atmosphere got the most satisfaction. At last, the survey method used in this paper was compared and discussed with the double bounded dichotomous choice contingent valuation which is broadly applied in relevant fields. The economic and societal performances yielded by the comprehensive environmental regulation were also previewed in order to provide theoretical bases for the establishment of concerned political measurements

* 江苏省环境保护厅重点科技项目 “环境价格体系研究” (2003086-2) 资助. 2006-07-16 收稿;2006-10-16 收修 改稿. 黄和平,男,1968 年生,博士, 副教授;E-mail: hphuang2004@163.com.

** 通讯作者;E-mail: jbi@ nju. edu.cn. 
and the management of regional environmental resource capitals.

Keywords: Lake Wuli; comprehensive environmental regulation; tour value (TV); contingent value method ( CVM) ; willingness to pay ( WTP)

旅游资源是一种特殊的资源, 其价值评估一直是资源定价研究中的重点和难点. 而其价值的高低往往 取决于高质量的自然美景、人文景观及风情民俗等,生态环境的保护和改善有利于这些特征的维持和提高. 科学、合理地核算旅游资源价值,则有利于旅游资源的开发和保护,有利于旅游开发投资的成本 - 收益分 析,亦为旅游持续管理和科学决策提供保障 ${ }^{[1]}$.

目前,国际上资源环境价值货币化核算的基本框架初步形成 ${ }^{[2-4]}$, 国内对旅游价值货币化核算也多有 尝试 ${ }^{[5-8]}$. 由于绝大多数环境物品或生态服务的公共物品特征以及外部性的存在, 使得对环境物品和生态 服务的价值评估不能用常规市场方法解决, 而 Davis ${ }^{[9]}$ 于 1963 年提出并得到迅速发展的条件价值评估法 (Contingent Value Method, CVM) 在这方面的研究中却越来越发挥着重要的作用 ${ }^{[10]}$.

CVM 是一种典型的陈述偏好评估法, 是在假想市场情况下,直接调查和询问人们对某一环境效益改善 或资源保护的措施的支付意愿 (willingness to pay，WTP)、或者对环境或资源质量损失的接受赔偿意愿 (willingness to accept compensation, WTA), 以人们的 WTP 或 WTA 来估计环境效益改善或环境质量损失的 经济价值. 与市场价值法和替代市场价值法不同, CVM 不是基于可观察到的或预设的市场行为,而是基于 被调查对象的回答. 直接询问调查对象的支付意愿既是 CVM 的特点,也是 CVM 的缺点所在. CVM 可用于 评估环境物品的利用价值和非利用价值, 并被认为是可用于环境物品和服务的非利用价值评估的唯一方 法 ${ }^{[11-14]}$, 是近 10 余年来国外生态与环境经济学中最重要的和应用最广泛的关于公共物品价值评估的 方法.

在利用 CVM 对旅游价值进行评估方面, 国内已有许多学者作了积极的探索, 如: 薛达元等在野外调查 的基础上利用 CVM 结合费用支出法和旅行费用法 ( TCM) 对长白山自然保护区生物多样性旅游价值进行 了评估,建立了旅游率与人口、收人、旅行费用及旅行时间等因变量之间的回归模型和 “供给 - 需求曲线”, 得出 1996 年长白山保护区生物多样性旅游价值为 43205 万元, 其中国内旅游价值 13783 万元, 国外旅游价 值 29422 万元 ${ }^{[5]}$. 陈浮等在实地调查基础上,运用支付意愿、旅行费用等方法组合对九寨沟风景区旅游价 值进行了初步核算, 认为旅游价值具有游移性、多元性和可耗性, 直接受旅游目标市场定位影响 ${ }^{[1]}$.

近年来,太湖富营养化现象日趋严重, 并经常爆发 “水华”事件. 太湖受污染最严重的区域为五里 湖 ${ }^{[15]}$. 通过 2001 年来数年的环境综合整治, 五里湖及其周边地区的环境条件已得到明显改善 ${ }^{[16]}$. 目前有 关五里湖的污染机理、治理工程及生态修复研究已取得多项成果 ${ }^{[17-22]}$. 但从环境资源学角度对其环境改 善所带来的各方面服务价值特别是旅游价值的研究还未见报道. 有鉴于此, 本文以无锡市五里湖环境综合 整治为例, 运用 CVM 和相关数学手段, 通过对受益周边地区居民及外地游客的问卷调查, 对周边旅游环境 的改善所带来的旅游支付意愿 (WTP) 及影响因素进行了评估和分析, 以期为当地环境改善和产业结构优 化提供参考,并为区域生态建设和环境经济政策的制定提供理论依据.

\section{1 研究区概况}

太湖是我国第三大淡水湖,五里湖则是梅梁湖 (太湖的一个湖湾) 伸入陆地的一片水域. 地处太湖北 部, 以宝界桥为界分东西两个湖区, 东西长约 $6 \mathrm{~km}$, 南北宽 $0.3-1.5 \mathrm{~km}$, 原湖面面积 $6.4 \mathrm{~km}^{2}$, 综合整治后面 积 $8.6 \mathrm{~km}^{2}$, 平面形状呈两头宽, 中间窄. 由于深处腹地, 相对封闭, 水体流动慢, 换水周期长, 自净能力较 差. 近二十年来, 随着沿湖地区工农业生产的迅速发展和人口增长, 使湖泊遭受污染的因素不断增多, 大部 分水质指标接近或超过地表水 $\mathrm{V}$ 类标准,水体富营养化严重,达到重富营养化程度. 对此,当地政府和相关 部门自 2002 年起对五里湖实施了环境综合整治工程, 取得了明显成效 ${ }^{[18-22]}$, 并对旅游环境的改善也起到 了较好的推动作用.

\section{2 问卷设计与调查}

选择五里湖景区作为研究范围,调查五里湖周边居民和外地游客对五里湖整治前后前来游玩的支付意 
愿. 采用随机抽样、面对面直接问卷调查的方法,样本量确定为 100 .

\section{1 问卷设计}

采用 CVM 问题格式设计问卷. 为尽量消除研究过程中由于各种原因带来的可能偏差, 笔者采取了以 下措施: 首先, 在充分了解五里湖环境综合整治的基础上,通过专家咨询和研究组讨论确定问卷的主要内容 和方式,并设计调查问卷初稿; 其次, 对调查人员进行严格培训和督导; 再次, 在五里湖环境综合整治的实施 者、管理者和周边居民及游客中多次组织小组讨论, 以改善问卷设计的内容和质量; 最后, 随即抽取 30 名五 里湖周边居民和游客对修改后的问卷进行预调查, 在预调查的基础上完善了问卷中问题的表述并确定问卷 最终稿 ${ }^{[10,23]}$.

问卷由 3 个主要部分组成: 被调查者的社会经济情况; 游客对五里湖景区满意度的调查; 游客对五里湖 整治前后前来游玩的支付意愿 (WTP). 在向游客询问他们的支付意愿之前, 由调查员将预先准备好的关于 五里湖综合整治前后的环境状况的图片出示给被调查者, 同时向被调查者介绍有关五里湖的整治情况、支 付费用的意义. 被调查者在充分理解其情况和意义后进行如下问卷调查 (图 1), 其中提问方式采用逐次递 进的办法,直至被调查者回答为“否”为止.

在您刚看了原来没有整治过的五里湖景象的图片或凭您以前的印象（当地居民）,您是否愿意花费下列选项的金额来五 里湖游玩一次? (费用包括门票、交通、饮食、住宿、风景点购买小礼品等)

(1) 免费 (是、否);(2)2 元 (是、否);(3)5 元 (是、否); (4)8 元 (是、否);(5) 15 元(是、否);(6) 30 元(是、否); (7) 50 元 (是、否); (8) 80 元(是、否); (9)150 元(是、否); (10)300 元(是、否);(11)500 元或以上(是、否)

在您刚看了已经整治过的五里湖景象的图片后,您是否愿意花费下列选项的金额来五里湖游玩一次?（费用包括 门票、交通、饮食、住宿、风景点购买小礼品等)

(1) 免费 (是、否); (2) 2 元 (是、否); (3) 5 元 (是、否); (4) 8 元 (是、否); (5) 15 元 (是、否); (6) 30 元 (是、否); ( 7 ) 50 元 (是、否);(8) 80 元 (是、否);(9) 150 元 (是、否); (10)300 元 (是、否);(11) 500 元或以上(是、否)

图 1 WTP 问卷调查

Fig. 1 Questionnaire on WTP

\section{2 调查实施}

CVM 的调查方式可以采取邮寄、电话访问、面对面调查等. 面对面调查虽然成本很高,但由于信息可以 当面反馈, 回收率及问卷质量相对较高 ${ }^{[24]}$. 此次调查采取的就是面对面调查方式,正式调查是在 2004 年的 9 月完成的. 具体时间是上午的 8-10 点、16-17 点和晚上 19-20 点. 在五里湖周边地区随机抽取 100 名 游客 (包括当地居民和外地游客) 作为调查对象, 调查的方式均采用面对面采访, 调查时间控制在 $15-25$ 分钟.

\section{3 调查结果与分析}

调查共获得有效问卷 91 份,有效回收率占 $91.00 \%$, 与国外同类研究相比, 效果较好 ${ }^{[25]}$. 在有效问卷 中,所有被调查者均表达了不同数目的支付意愿. 被调查者的主要社会经济特征 (表 1) 基本涵盖了五里湖 周边居民及游客的各个层面,具有较好的代表性.

表 1 五里湖周边被调查游客主要社会经济特征

Tab. 1 Main social and economic characteristic of the surveyed travelers around Lake Wuli

\begin{tabular}{cccccc}
\hline 年龄 & 人数 & 教育程度 & 人数 & 年均收人 & 人数 \\
\hline $10-20$ 岁 & 11 & 中小学或以下 & 28 & 1 万元以下 & 23 \\
$21-30$ 岁 & 40 & 大专 & 22 & 1 万 -3 万元 & 30 \\
$31-50$ 岁 & 24 & 大学 & 32 & 3 万 -5 万元 & 20 \\
50 岁以上 & 16 & 技校或其他 & 9 & 5 万元以上 & 18 \\
\hline
\end{tabular}

按照意愿调查法对数据进行分析处理, 首先根据调查所获得的数据, 对数据进行笁选, 清除无效问卷, 
再求取 WTP 的平均值,进而测算五里湖环境资源所具有的价值. 由于本次调研时, 综合整治工程刚完成, 軣湖公园也未正式对外开放, 游客较少, 旅游市场还不完备. 故针对本次调查样本大小和特征, 采取以下方 法对数据进行分析:不区分被调查者类型,列出调查所有样本频率分布,把不同规模的支付意愿声明与人数 对应出来,以求取环境资源所带来的旅游价值.

\section{1 游客对五里湖整治前后前来游玩的支付意愿}

本次调查所采用的频率分析法是根据被调查者在环境综合整治前后愿意支付的金钱数额来确定五里 湖游客支付意愿的具体情况. 根据调查在五里湖整治前一定会前来游玩的支付意愿, 绘制出被调查者在各 个支付金额(下限)上支付人数频率分布图(图 2).

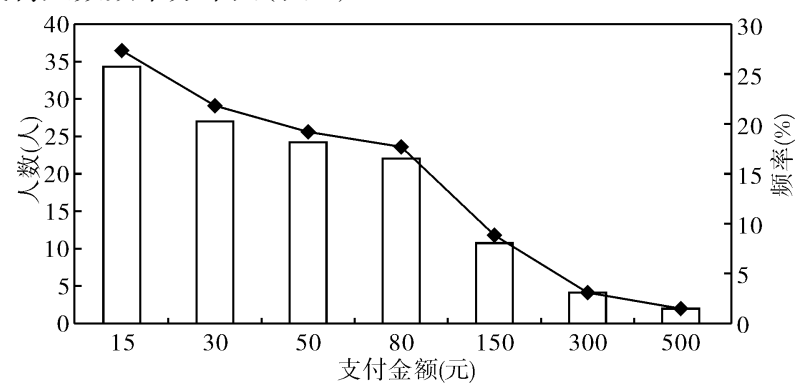

图 2 调查游客支付意愿下限频率分析

Fig. 2 Frequency distribution of inquisitional tourists' WTP lower limit

据此可以计算出游客的支付意愿下限为:

$$
E\left(W T P_{1}\right)=\sum_{i=1}^{7} P_{i} \times b_{i}=65.56 \text { 元 }
$$

式中, $P_{i}$ 为各金额点人数的分布频率, $b_{i}$ 为各金额点的支付意愿数额, $E\left(W T P_{1}\right)$ 为支付意愿的下限.

再根据调查在五里湖整治后前来游玩的支付意愿,绘制出游客在各个支付金额 (上限) 上支付人数频 率分布图(图 3).

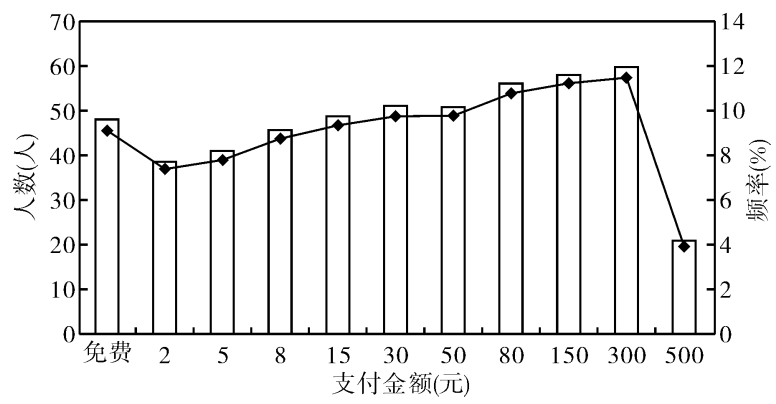

图 3 调查游客支付意愿上限频率分析

Fig. 3 Frequency distribution of inquisitional tourists' WTP upper limit

同样可得到游客的支付意愿上限为：

$$
E\left(W T P_{2}\right)=\sum_{i=1}^{7} P_{i} \times b_{i}=90.44 \text { 元 }
$$

式中, $P_{i}$ 为各金额点人数的分布频率, $b_{i}$ 为各金额点的支付意愿数额, $E\left(W T P_{2}\right)$ 为支付意愿的上限.

\section{2 游客支付意愿的特点分析}

为便于分析被调查者的年龄、家庭年收人和受教育程度三个社会经济变量对支付意愿的影响程度,下 面仅用 $W T P$ (上限)来反映支付意愿随着这几个社会经济变量变化而变化的趋势(图 4). 可以看出,游客的 

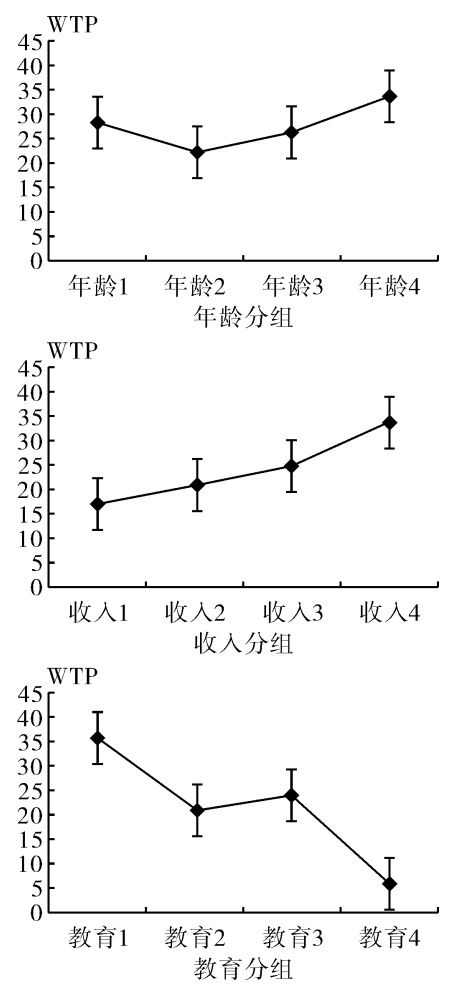

图 4 支付意愿与社会经济变量关 系分析 (年龄分组:组 1:10-20 岁; 组 2:21-30 岁; 组 3:31-50 岁; 组 4:51 岁及以上; 收人分组: 组 $1: 10000$ 元以下; 组 $2: 10000-$ 30000 元; 组 $3: 30000-50000$ 元; 组 4:50000 元及以上; 教育分组: 组 1 : 小学及中学; 组 2 : 大专; 组 3 : 大学; 组 4 : 技校及其他)

Fig. 4 Analysis of WTP and social economic variables

\section{4 五里湖旅游支付意愿的影响因素分析}

为进一步探讨五里湖旅游支付意愿的影响因素, 笔者在游客对五 里湖景观满意度的调查中,列出了购物、住宿、娱乐设施、空气质量等近 10 种因素一并置入游客问卷调查表 中, 以分析游客对五里湖旅游过程中影响因素的满意程度 (图 5), 从而进一步探讨影响游客支付意愿的主 要原因. 可以看出,游客对五里湖景区满意度表现最差的是娱乐设施,其次是购物、住宿的便利性和水面的 表观形象, 表现最好的是空气质量和其安静的氛围. 说明在五里湖景区的建设过程中, 亟待加强的是娱乐 设施及购物、住宿等配套设施的建设,水质也有待于进一步改善. 上述方面的改进也必将有利于游客支付 意愿的提高.

\section{4 结语}

通过数年的环境综合整治,五里湖及其周边地区的环境条件已得到明显改善 ${ }^{[20]}$, 由此给当地带来的经 


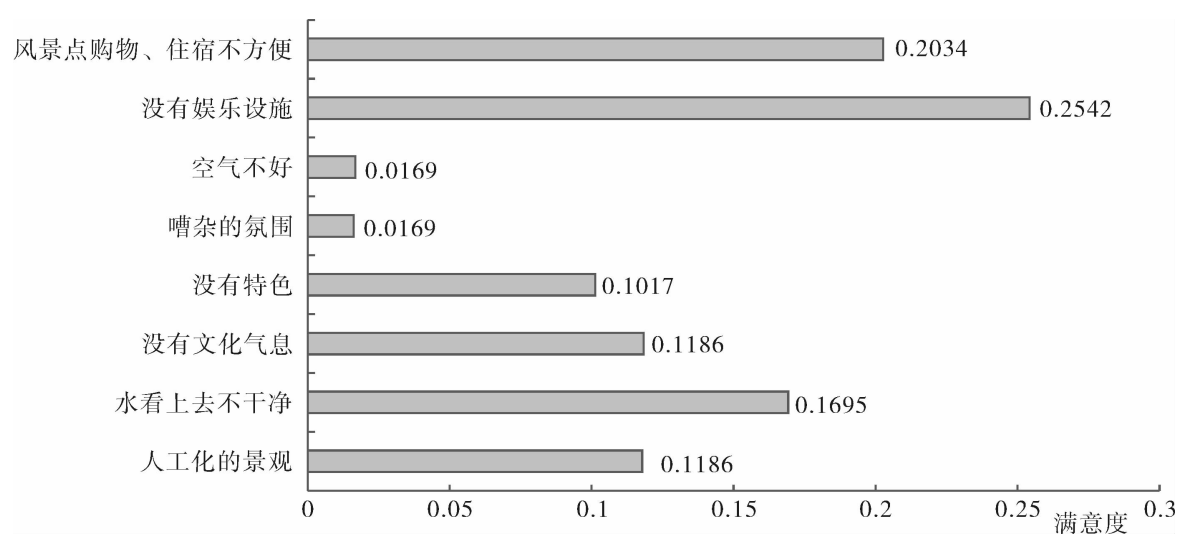

图 5 游客对五里湖景区满意度的调查结果

Fig. 5 Inquisitional result of tourists' satisfaction with Lake Wuli sight

济效益也十分可观, 仅从其旅游业就可每年增加 2.49 亿元的收人, 本文限于主题及篇幅的限制, 虽未对其 成本 - 效益分析进行评价, 但环境综合整治对区域经济绩效的提高及产业结构的调整是有益的. 另一方面, 五里湖环境综合整治给当地带来的社会绩效也有突出作用, 这从游客对五里湖景区的满意度调查结果中也 可以看出,为“生态环境保护优先, 人与自然和谐相处”树立了一个典范.

本文的分析结果进一步证明,环境就是资源、资产和资本 ${ }^{[28]}$, 当地政府通过环境综合整治工程,从而形 成“水环境治理投人 - 环境改善出效益 - 以效益补偿治理资金 - 水环境治理再投人” 的良性循环,这也为 当地政府的环境经济政策的制定和环境资源资本的运作及管理提供了参考依据. 从方法上看,本文采取的 面对面直接调查法及问卷设计类似于双边界二分式条件价值法 (double bounded dichotomous choice contingent valuation method), 但比双边界二分式 CVM 又更进一步,尽管它是 CVM 法中评估结果较精确的一种方 法 ${ }^{[29]}$, 但由于其为被调查者提供的选择只有两个,也就是它先为被调查者提供一个投标值, 问其是否愿意 支付. 如果被调查者的回答是 “是”, 则为其提供另一个较高的投标值; 否则为其提供另一个较低的投标值. 但在现实情况中, 部分被调查者的选择多于两个, 本文设计的从零起点到无穷的多项选择则避免了这一缺 陷,基本能涵盖被调查者所有的选择,当然这方面的研究和应用还有待于进一步探讨.

\section{5 参考文献}

[1] 陈 浮, 张 捷. 旅游价值货币化核算研究一九寨沟案例分析. 南京大学学报 (自然科学版), $2001,37(3): 296-303$.

[2] E R M. The valuation of biodiversity in U. K forest. London: Environmental Resources Limited, 1993: 1 17.

[3] United Nations. System of national accounts 1993. New York: United Nations Press, 1994: 4 - 20.

[4] United Nations. Integrated environmental and economic accounting. New York: United Nations Press, 1992: 5 - 79 .

[5]薛达元,包浩生,李文华. 长白山自然保护区生物多样性旅游价值评估研究. 自然资源学报, 1999, 14 (2) : $140-145$.

[6] 王连茂,尚新伟. 香山公园森林游憩效益的经济评价. 林业科学, 1993, 29(3): 66 - 71.

[7] 薛达元. 生物多样性经济价值评估. 北京: 中国环境科学出版社,1998: 5-122.

[8] 张 茵, 蔡运龙. 基于分区的多目的地 TCM 模型及其在游憩资源价值评估中的应用一一九寨沟自 然保护区为例. 自然资源学报,2004, 19(5): 651-661.

[9] Davis R K. Recreation planning as an economic problem. Natural Resources Journal, 1963, (3) : 239 -249 . 
[10] 张志强, 徐中民, 程国栋. 条件价值评估法的发展与应用. 地球科学进展, 2003, 18(3): 454-463.

[11] Loomis J B, Walsh R G. Recreation economic decisions: comparing benefits and costs. 2nd ed. Pennsy lvania: Venture Publishing Inc, 1997.

[12] Bateman I J, Willis K G eds. Valuing environmental preferences: theory and practice of the contingent valuation method in the US, EU, and developing countries. New York: Oxford University Press, 1999.

[13] Asafu-Adjaye J. Environmental economics for non-economists. Singapore: World Scientific Publishing Co Pte Led, 2000.

[14] Bjornstad D J, Kahn J R eds. The contingent valuation of environmental resources: methodological issues and research needs. Cheltenham: Edward Elgar Publishing Limited, 1999.

[15] 丁 玲, 逢 勇,赵棣华等. 调水工程对五里湖水环境影响分析. 河海大学学报(自然科学版), 2003, 31(4) : $366-369$.

[16] 朱 喜. 从五里湖谈太湖水污染防治. 中国水利,2004, (14) : 16-18.

[17] 范成新,秦伯强, 孙 越. 梅梁湖和五里湖水 - 沉积物界面的物质交换. 湖泊科学, 1998, 10(1): 73 -78 .

[18] 顾 岗,陆根法. 太湖五里湖水环境综合整治的设想. 湖泊科学,2004, 16(1): 56-60.

[19] 颜昌宙,许秋瑾,赵景柱等. 五里湖生态重建影响因素及其对策探讨. 环境科学研究, 2004, 17 (3): $44-47$.

[20] 沈亦龙. 太湖五里湖清淤效果初步分析. 水利水电工程设计,2005, 24(2): 23-26.

[21] 朱德明,曲福田. 无锡五里湖水环境综合整治的启示. 环境保护,2005, (10): 60-65.

[22] 陈开宁,包先明,史龙新等. 太湖五里湖生态重建示范工程一一型围隔试验. 湖泊科学, 2006, 18 (2) : $139-149$.

[23] 金建君,王志石. 澳门固体废物管理的经济价值评估. 中国环境科学, 2005, 25(6) : 751-755.

[24] 程淑兰,石敏俊,王新艳等. 应用两阶段二分式虚拟市场评价法消除环境价值货币评估的偏差. 资源 科学, 2006, 28(2): $191-197$.

[25] John O' Neill. Management without prices: The monetary valuation of biodiversity. AMBIO, 1997, 26(8) : $67-71$.

[26] 邓德仁. 赴江苏省无锡市参加 “太湖水污染控制与水体修复及工程示范” 课题验收会的情况介绍. ( http://www. kmsti. net. cn/gwt200607. htm).

[27］江苏省统计局编. 江苏省统计年鉴(2004). 北京:中国统计出版社,2004: 289 .

[28] 孙志军,洪银兴. 以科学发展观统领全面小康社会建设. 南京: 南京大学出版社,2006: $342-346$.

[29] Hanemann W, Loomis J, Kannienen B. Statistical efficiency of double bounded dichotomous choice contingent valuation. American Journal of Agricultural Economics, 1991, 73(4) : 1255 - 1263. 